\title{
EL POLIEDRO TRANSPARENTE O LA RIQUEZA DE LAS IMÁGENES CINEMATOGRÁFICAS
}

\author{
Ángel Luis Hueso Montón \\ Universidade de Santiago de Compostela
}

ORCID: https://orcid.org/0000-0001-6055-939X

\section{RESUMEN}

Uno de los rasgos más representativos del cine es saber aglutinar aportaciones de diferentes campos, lo que da como resultado películas en las que se muestra una riqueza que va más allá de la mera suma de contribuciones individuales; es lo que denominamos como "poliedro cinematográfico". En este trabajo analizamos una serie de películas que son testimonio de la riqueza artística del cine, pertenecientes a épocas diferentes, con planteamientos diversos y realizadas por distintos directores; se trata de La muerte cansada (Fritz Lang, 1921), Orfeo (Jean Cocteau, 1950), El manuscrito encontrado en Zaragoza (Wojciech Has, 1964) y Goya en Burdeos (Carlos Saura, 1999).

Palabras clave: Cine, riqueza artística, "poliedro cinematográfico", Lang, Cocteau, Has, Saura

\section{ABSTRACT}

One of the most representative features of cinema is its ability to provide a focal point for contributions from different fields, a quality that results in films with a value that goes well beyond the mere sum of individual contributions and to which I refer as the "cinematographic polyhedron". In this study we analyse a series of films that attest to cinema's artistic value and which belong to different periods, offer diverse approaches, and were made by different directors: Destiny (Fritz Lang, 1921), Orpheus (Jean Cocteau, 1950), The Saragossa Manuscript (Wojciech Has, 1964) and Goya in Bordeaux (Carlos Saura, 1999).

Keywords: cinema, artistic value, "cinematographic polyhedron", Lang, Cocteau, Has, Saura

Una de las situaciones más apasionantes que un investigador puede vivir, es cuando se sitúa ante una obra de arte (de cualquier tipo) y se interroga sobre los diferentes aspectos que confluyen en ella. Si esto sucede en cualquier manifestación artística, adquiere especial importancia en el mundo del cine.

Cuando nos referimos a la imagen animada, estamos hablando de una forma de hacer arte en la que cada obra se nos presenta como aglutinadora de muy diversas perspectivas o contribuciones; destaca de manera especial la dialéctica de unidad y diversidad que encontramos en cada filme, de tal forma que cuando nos acercamos a una película, a la vez que la consideramos como un todo unitario, podemos encontrar en la misma una diversidad de interrogantes y respuestas que nos testimonian la pluralidad de confluencias que hay detrás de cada imagen animada y que se ejemplifica en la multitud de contribuciones personales. ${ }^{1}$

En alguna ocasión hemos hablado de esta circunstancia denominándola como "poliedro cinematográfico"; al igual que la figura geométrica de referencia está formada por una serie de polígonos que constituyen sus diversas caras y que son responsables de la tridimensionalidad del poliedro, en una película nos encontramos con 
una serie de aportaciones diferentes entre sí, a las que probablemente concedemos una valoración diversa, pero que se presentan interrelacionadas, de forma que de manera semejante al modelo de referencia, en el cine cada aportación soporta, en mayor o menor grado, a las restantes.

En primer lugar, debemos resaltar el carácter industrial y comercial que posee este mundo del cine, y que lleva a que se cree un entramado económico de indudable importancia a lo largo de todo el siglo XX, el cual adquiere matices diferentes de acuerdo con las condiciones de cada momento y país y que, a su vez, condiciona de manera radical todas las facetas que pueden considerarse posteriormente.

Junto a ello encontramos el soporte técnico que ha dado forma a las películas y que, a su vez, se ha visto sometido a una dinámica trasformadora continua, de forma que un factor que no puede dejarse de lado en ningún momento es considerar los condicionantes tecnológicos que inciden sobre cada filme concreto y su lanzamiento al mercado.

Por otro lado, constatamos que estos factores económicos y técnicos tiene unas consecuencias lingüísticas y estéticas; nadie puede negar que las estructuras narrativas del cine poseen una peculiaridad y riqueza inconmensurable, lo mismo que percibimos una estética propia que surge de los recursos expresivos de esa imagen en movimiento. Sin embargo, no podemos considerar al cine como un ente aislado de las implicaciones del mundo cultural en el que surge, antes al contrario, encontramos en las imágenes una presencia, mayor o menor según los casos, de las implicaciones artísticas, literarias, filosóficas de cada sociedad y momento.

Ya se puso de manifiesto por parte de Jean Mitry el necesario equilibrio entre todas estas aportaciones $y$, sobre todo, entre aquellas que pueden parecer contrapuestas como son la industrial/económica y la artística. Lo expresó de manera meridiana al decir:

Únicamente la rentabilidad permite asegurar la continuidad de la producción y, como consecuencia, todo progreso posible, ya técnico, ya artístico, hallándose a menudo uno en función del otro. Hay que señalar que el cine no se ha convertido en un arte sino gracias a, y en la medida de, su industrialización. Pero tampoco hay que olvidar que no podría ser una industria sino fuese un arte un espectáculo de arte, un relato en imágenes animadas. ${ }^{2}$

Pero todo ello tendría un valor relativo si ignoráramos que las películas surgen en un contexto social muy preciso, marcado por unas concepciones ideológicas, económicas, culturales o religiosas propias de cada sociedad; además, no podemos dejar de lado que los filmes tienen unos destinatarios muy precisos como son los potenciales espectadores, aspecto este marcado por un deseo de universalidad e intemporalidad pues serán generaciones sucesivas y en cualquier lugar del mundo las que puedan contemplar esas obras audiovisuales.

A la vez, y como hacíamos mención anteriormente, el cine se ha visto inmerso en una transformación inexorable a lo largo de toda su existencia, de tal forma que los cambios internos que ha ido experimentando han tenido consecuencias en diferentes aspectos de su manera de presentarse ante el público. Este aspecto, que podría considerarse como anecdótico, tiene a nuestro modo de ver una importancia capital, pues es testimonio de un profundo dinamismo interno en el que la técnica es fundamental, de un deseo de adecuarse a los cambios sociales que se producen a su alrededor y de ser un catalizador que aglutine las aportaciones de otros campos culturales haciéndolos propios.

Tenemos que reconocer que es muy difícil conceder igual atención a todas estas facetas que acabamos de enumerar y que están presentes en el mundo del cine, lo que nos lleva a la necesidad de fragmentar nuestra preocupación de acuerdo con los intereses puntuales en cada momento.

En esta ocasión vamos e centrar nuestra atención en poner de relieve que las películas poseen una riqueza que deriva, en gran parte, de la asunción de aportaciones procedentes de ámbitos culturales diferentes que son reinterpretados por las imágenes y, sobre todo, dotados de una entidad nueva que deriva de las características propias de este medio expresivo.

Teniendo en cuenta todos estos factores vamos a intentar dejar testimonio de esta riqueza 
interna del cine a través del análisis de cuatro películas, a nuestro modo de ver, especialmente significativas. Pertenecen a momentos diferentes (e importantes) de la historia del cine a lo largo del siglo pasado, a países y ambientes culturales diversos y a la responsabilidad de directores dotados de una concepción peculiar de este medio icónico, por lo que consideramos que, más allá de su importancia individual, se nos presentan como un conjunto valioso y significativo de lo que puede ser la creación de una forma artística nueva que hunde sus raíces en las aportaciones de la cultura tradicional.

Las obras que vamos a comentar son La muerte cansada (Der Müde Tod) dirigida por Fritz Lang en 1921, Orfeo (Orphée, 1950) de Jean Cocteau, El manuscrito encontrado en Zaragoza (Rekopis znaleziony w Saragosie) dirigida en 1964 por Wojciech J Has y, finalmente, Goya en Burdeos con realización de Carlos Saura en 1999.

\section{La muerte cansada (Der Müde Tod, Fritz Lang, 1921)}

En un momento especialmente significativo del pasado siglo XX como son los primeros años de la década de los veinte, y en plena efervescencia de la recién nacida República de Weimar, surge la película que comentamos y que se inserta en el movimiento expresionista que domina el cine alemán de estos años.

Lo primero que llama la atención es encontrarnos con una obra que responde a muchas de las claves de este movimiento artístico y de su aplicación cinematográfica. En esta línea y a nivel argumental, no puede sorprendernos constatar la fuerza de la tradición romántica dentro de la sociedad y la cultura alemana, de forma que muchas de las claves con las que se desarrolló aquel movimiento del XIX permanecen en el alma alemana muchas décadas después. Dentro de estas tradiciones adquiere una especial importancia la presentación y reflexión sobre el amor y la muerte, pero no considerados de una manera abstracta sino materializados y cercanos a nosotros.

El papel desempeñado por la muerte se llega a convertir en el eje central de la película. Es muy significativo el propio título original ("Der Müde Tod", La Muerte cansada), cuya traducción nos presenta dos peculiaridades de este personaje: el hecho de que se trata de un hombre (de acuerdo con el género que posee la muerte en la lengua germánica) y está "cansada" de tener que actuar de manera continua bajo un mandato superior. ${ }^{3}$

La humanización de la Muerte es especialmente significativa, no sólo en sus gestos y comportamiento ${ }^{4}$ sino de manera especial en su actitud hacia los humanos (en este caso concreto hacia la joven protagonista) y, sobre todo, con la idea que nos trasmite de estar subordinada a un poder superior que le exige poner fin a la vida de cada individuo, lo que le conduce a un cansancio permanente. ${ }^{5}$

Se ha resaltado que esta forma de ver el paso al más allá de una manera cercana suaviza su dureza, pues nos encontramos con situaciones llamativas como es el hecho de que la joven llegue a regatear con la Muerte y consiga que le ofrezca tres oportunidades para salvar a su amado o que dialogue con la protagonista planteándole la inexorable situación en que se encuentra.

Pero la Muerte no la veremos de forma aislada, antes al contrario se nos ofrecerá con una importante contraposición: el Amor. ${ }^{6}$ Encontramos, una vez más, una de las claves románticas más representativas y que se considera como definidora de muchas de las historias trasmitidas por aquel movimiento. Todo el film viene a ser un diálogo entre ambos conceptos. una lucha por ver cual de ellos alcanza el triunfo sobre el opuesto, una dinámica que se ve abocada a un desenlace en el que el equilibrio se nos hace patente.

Porque no podemos dejar de lado que aunque la fuerza de la Muerte parece definitiva y conduce a un final luctuoso, frente a ella se levanta el poder inconmensurable del Amor; recordando el texto bíblico se nos dice que "Es fuerte el Amor como la Muerte" $"$, lo que conduce a una situación final cuando menos llamativa, puesto que aunque la Muerte no haya sido derrotada, el Amor también resulta victorioso al lograr que ambos amantes permanezcan unidos para la eternidad. ${ }^{8}$

La indudable fuerza de esta temática se nos presenta con una estructura narrativa que alcanzará gran predicamento en este cine expresionista; la manipulación espacio-temporal es uno de 
los elementos más novedosos en este cine, de manera que no puede sorprendernos que en $L a$ muerte cansada el tiempo adquiera una especial importancia.

Si por una parte tenemos la trilogía formada por las tres historias en la que la protagonista intenta salvar a su amado de la muerte sin conseguirlo, por otra se produce una interesante distorsión temporal cuando la muchacha va a tomar el veneno que la conducirá junto a su pareja (son exactamente las once de las noche lo que vemos en el reloj y las palabras del sereno) para tener su encuentro con la Muerte, vivir esa triple aventura y volver al mismo punto de partida.

Gracias a estas situaciones se reafirma el carácter simbólico de la historia, pues no solamente los protagonistas son denominados como "los Amantes", sino que viven momentos similares ambientados en lugares y épocas diferentes (mundo persa, Venecia renacentista y China fantástica) con lo que se nos ofrece la reflexión de que esta dialéctica es constante en el tiempo y el espacio.

Se ha resaltado que este simbolismo representa un paso hacia modelos narrativos que alcanzarán gran predicamento en el cine alemán de los años centrales de aquella década; el denominado "Kammerspielfilm" nos ofrecerá un cine que pretende ser una reflexión sobre el hombre y sus situaciones vitales, más allá de los elementos concretos que se nos visualizan, lo cual se constata de manera notable en el film que comentamos.

Pero junto a ello, las tres historias que viven los protagonistas dan pie al director y guionista para ofrecer al espectador una variedad de ambientes que suponen un gran atractivo; serán un tipo de historias que tendrán una gran presencia en el cine silencioso de aquellos años, puesto que los ambientes renacentistas, los mundos exóticos y los temas fantásticos estarán en algunos de los grandes filmes del momento (recordemos El ladrón de Bagdad (The Thief of Bagdad, 1924, Raoul Walsh) interpretado por Douglas Fairbanks en el que se siguen algunos de los avanzados trucos de los estudios alemanes).

Merced a esta variedad temático-geográfica se supera la limitación con que arrancaba el film al centrase en una pequeña población y a un nú- mero concreto de personajes, que de este modo vienen a ser el mero detonante de la historia que así es superada y alcanza ese contexto generalista que multiplica el interés de la película.

La riqueza espacial se reafirma considerando la importancia de los decorados y su sentido en cada momento de la obra. No podemos ignorar la contribución de algunos de los grandes decoradores del momento, como es el caso de Walter Röhring (responsable de los decorados de la historia alemana), Hermann Warm (episodios árabe y veneciano) y Robert Herlth (episodio chino); si los dos primeros venían de contribuir al impacto de El gabinete del doctor Caligari (Das Cabinett des Dr. Caligari, Robert Wiene, 1920), Herlth colaboraría más adelante con Murnau en obras como El último, (Der letzte Mann, 1924) y Fausto (Faust- eine deutsche Volkssage, 1926). ${ }^{9}$

No se trata solamente de que se construyeran decorados que dotaban de corporeidad a cada historia concreta, sino de que los acontecimientos se integraban perfectamente en el contexto arquitectónico; buen ejemplo de ello es la fisicidad del gran muro construido por la Muerte que separa de forma radical el mundo de los vivos y de los muertos y ante el cual se hace evidente la pequeñez de la protagonista que intenta sortearlo. ${ }^{10}$ Algo similar puede apuntarse de cada uno de los ambientes en que se desarrollan las andanzas de los protagonistas y que en casos como el mundo chino se nos presenta con una gran riqueza de detalles (fig. 1).

Junto a la corporeidad arquitectónica no podemos ignorar las influencias pictóricas entre las que alcanza un nivel destacado la inspiración en las obras de Caspar David Friedrich que con sus paisajes románticos será un referente en muchos momentos del film. ${ }^{11}$

Pero este mundo arquitectónico, aún con su importancia, sería muy poco si dejáramos de valorar la importancia del uso de la luz. Encontramos, una vez más, una integración en determinadas tendencias del mundo escénico del momento; la importancia del claroscuro que lleva al autor a apartarse de los tonos medios de los grises adquiere, no sólo, un carácter narrativo sino una fuerza expresiva y simbólica (oposición entre el fuego y la sombra) que es un importante soporte para la acción.12 
A ello se une el hecho de que Lang ha comprendido de manera radical la forma en que la luz puede contribuir a crear una atmósfera13, circunstancia que será capital en el desarrollo posterior del cine alemán; el carácter expresivo de la luminosidad contribuirá a la creación de ambientes y personajes que serán capitales en la historia de este medio, de forma que su incidencia posterior en géneros (terror, policíaco), directores y fotógrafos será constante hasta el momento presente.

Decorados y luz. Elementos que en el teatro de aquellos años encontraron una utilización sorprendente en manos de un genio de la puesta en escena: Max Reinhardt. La importancia de sus contribuciones desbordaron los límites del teatro para incidir de manera decisiva en otros campos de representación y, en concreto, en el cine. El equilibrio entre los decorados y la forma de iluminarlos para darles vida, la iluminación de los personajes dentro de la escena, la búsqueda de un sentido más allá de lo inmediato serán factores que Reinhardt llevará de manera radical a sus puestas en escena y que serán inspiradoras de muchos cineastas y de manera especial de Fritz Lang. ${ }^{14}$

El equilibrio entre todas estas aportaciones (temáticas, narrativas, técnicas, estéticas) ponen de manifiesto que la ubicación de La muerte cansada en un momento preciso del cine alemán de los años veinte va más allá de lo meramente anecdótico y que, por el contrario, explica la importancia que adquirió el film desde el mismo momentos de su estreno y lo que supuso en la carrera profesional de su director.

\section{Orfeo (Orphée, Jean Cocteau, 1950)}

El secreto de los secretos.

Los espejos son las puertas por las que la Muerte viene y va

Esta frase pronunciada por Heurtebise cuando intenta explicar a Orfeo cómo la Muerte se ha llevado el cuerpo de Eurídice, es una de las grandes claves sobre la que Jean Cocteau construyó su apasionante reflexión sobre la muerte y el amor inserta en su interpretación del mito de Orfeo.

La personalidad de Cocteau y su dedicación artística en la que abordó múltiples campos en-

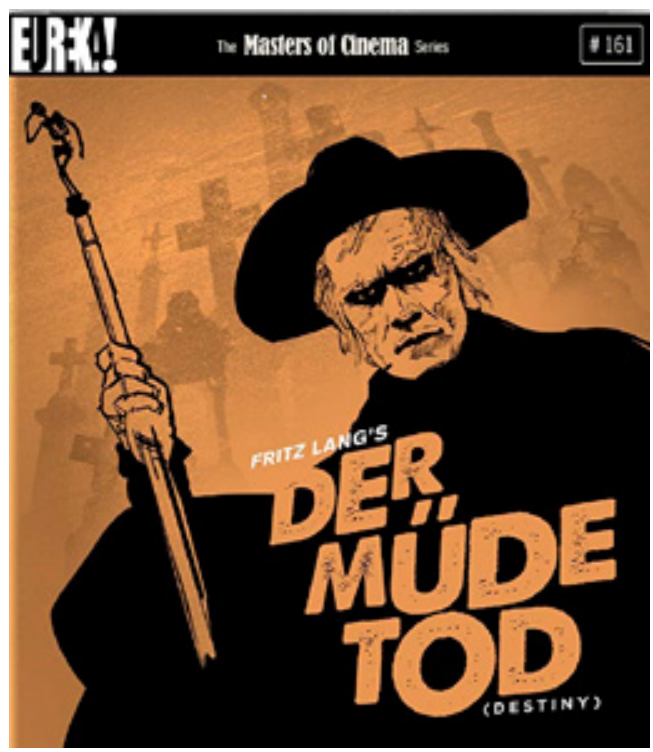

Fig. 1. Der Müde Tod, La Muerte cansada, Fritz Lang, 1921

cuentra una magnífica plasmación en el Orfeo que comentamos; desde los títulos de crédito dibujados por el mismo con su estilo vanguardista hasta los textos que se trasmiten por la radio y que nos hablan de una poesía totalmente rupturista, todo en el film nos presenta una continua reflexión sobre lo que son los caminos expresivos del mundo contemporáneo y que alcanzaron, en manos de este creador, un nivel verdaderamente sorprendente.

No es anecdótica, antes al contrario, la preocupación de Cocteau por el mito del rapsoda griego, puesto que será en tres películas, además de otras múltiples referencias, en las que se acercará al mismo; La sangre de un poeta (La sang d'un poète, 1931) y Le testament d'Orphée (1960) forman, junto a la película que comentamos, una trilogía extendida a lo largo de los años y que denota esa inclinación constante en nuestro autor.

Y ello lo hace ofreciéndonos su visión cinematográfica más rica, sugestiva y, sobre todo, personal, aquella en la que se funden una serie de tendencias que alcanzan un nivel de totalidad en Orfeo; serán el cine de vanguardia, el impresionismo fantástico de tradición francesa, el melodrama teatral y el rodaje en calles y escenarios 


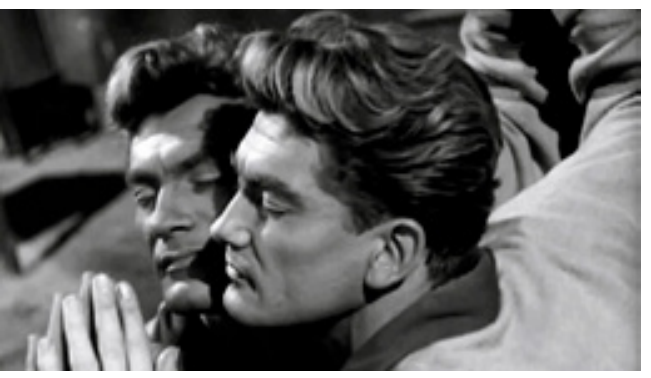

Fig. 2. Orphée, Jean Cocteau, 1950

naturales estilo neorrealismo ${ }^{15}$, elementos todos ellos de interés individual pero que integrados en su cine consiguen una singularidad fácil de percibir.

Lo primero que llama la atención es la utilización de una iconografía totalmente contemporánea, en la que los personajes y situaciones de las leyendas órficas responden al momento concreto de la realización del film. Los automóviles, las motos (los simbólicos ángeles de la muerte), la radio como comunicación poética, la alta costura que luce la Muerte, el tribunal del más allá, los bares de poetas claramente existencialistas (es significativa la presencia de una cantante como Juliette Greco dando vida a Aglaonice, la líder del Club de las Bacantes) son elementos que acercan la tradición clásica a la época presente, de forma que se evidencia la permanencia de los principios que subyacen en el mito, por encima del paso de los tiempos.

En esta búsqueda de elementos actuales es significativo que cuando se nos ofrece la "realidad" del más allá se hace mediante imágenes de un mundo destruido, ruinas que parecen restos de una civilización que existió en otras épocas, pero que posee muchos paralelismos con las imágenes que se nos habían ofrecido unos años antes como testimonio del final de la segunda guerra mundial (si hacemos abstracción de la iluminación, las imágenes son muy similares a las ofrecidas por Roberto Rossellini en su obra Alemania, año cero (Germania, anno zero, 1948).

Resulta curioso que casi treinta años después de La muerte cansada volvamos a encontrarnos con una reflexión, muy diferente es verdad, sobre la dialéctica que surge entre la Muerte y el Amor. En esta ocasión los cuatro personajes fundamentales (Orfeo, la Muerte de Orfeo, Eurídice y Heurtebise) crean un entramado en el que las inclinaciones amorosas se cruzan y en el que alcanzar la felicidad se plantea como una meta, sino inalcanzable, por lo menos muy difícil. Es muy interesante como Cocteau nos presenta el dilema de Orfeo ante el amor de Eurídice y el manifestado por la Muerte (esplendorosa y sugestiva María Casares) hacia él, lo mismo que sucede cuando Heurtebise declara su amor hacia Eurídice.

Y ello porque cada una de las parejas pertenecen a mundos diferentes. Mientras que lo cotidiano se nos ofrece como algo que parece vida pero no lo es, la fuerza de la muerte hace que nos acerquemos a un mundo que no lo parece pero está lleno de realidad, aunque sea distinta de la que conocemos los mortales. ${ }^{16}$ Es en este campo en el que Cocteau nos ofrece una demostración de su dominio sobre las formas expresivas de la propia imagen cinematográfica, llevando a efecto aquellas palabras que había escrito cuando decía: "No se trata de soñar dormidos sino de soñar despiertos. El realismo de lo irreal es más verdadero que la verdad". ${ }^{17}$

La originalidad del planteamiento de Cocteau es que la relación entre estas claves que proceden de un mundo clásico reconvertido al presente, son visualizadas mediante un recurso de gran plasticidad, cargado de sentidos diferentes, en el que los protagonistas se pierden casi como simples marionetas y que abre caminos de reflexión siempre sorprendentes. Nos referimos a los espejos.

El espejo se convierte, realmente, en el protagonista de esta obra sobre todo teniendo en cuenta la diversidad de matices con que se nos presenta; podemos considerar, en primer lugar, el más sencillo e inmediato, cuando lo vemos como una mera confrontación entre un personaje y su propia imagen reflejada en aquella superficie, con lo que se produce una lucha entre la tendencia a la tridimensionalidad y el carácter rígido y duro del espejo (y la pantalla). ${ }^{18}$ Esta situación viene a reafirmar que nos encontramos en un mundo tangible, configurado por elementos cotidianos que se nos ofrecen en sí mismos y en su reflejo preciso, de forma que nos enfrentamos con la realidad de lo humano y su finitud (fig. 2). ${ }^{19}$

Pero, sobre todo, el espejo se nos presenta como umbral o camino para pasar de un mundo 
a otro, para llegar a otro lugar que está más allá de su propia superficie ${ }^{20}$; la posibilidad del paso a la "otra realidad" que representa el mundo de la muerte, se nos ofrece rompiendo esa rigidez inicial que tiene todo espejo, lo cual se logra a través de fórmulas muy diferentes (es llamativo que no se repite ninguna fórmula para traspasar el espejo ${ }^{21}$ ) que representan matices en la interpretación de una situación única.

La ruptura del espejo (y su posterior recomposición) por parte de la Princesa o los guantes que penetran en el agua para facilitar el paso de Orfeo son ejemplos muy llamativos de lo que supone pasar a otra realidad; la efectividad de estas fórmulas ha hecho que sean imágenes que singularizan todo el film y que lo han representado para generaciones posteriores.

Además nos encontramos que en ese otro mundo no tiene cabida los mismos parámetros espacio-temporales con los que nos movemos en nuestra realidad; el concepto de espacio no existe de la misma forma que en nuestra realidad (así se lo dice Heurtebise a Orfeo cuando éste le pregunta si van muy lejos) y lo mismo sucede si nos fijamos con el paso del tiempo, pues se produce una clara distensión del mismo testimoniada en las seis campanas del reloj y la carta que deposita el cartero en el buzón que oímos y vemos cuando Orfeo traspasa el espejo y cuando regresa.

Los límites entre estos dos mundos corresponden a lo que Cocteau denomina como "la zona", un territorio donde no estamos muertos ni vivos del todo, una tierra de nadie transitada por sonámbulos ${ }^{22}$; son llamativos los recursos que utiliza el director para ofrecernos este mundo, utilizando luces y sombras con unos equilibrios contrastados, a la vez que nos ofrece momentos de realismo lumínico para asemejarse a nuestra realidad.

La fusión de todos estos recursos técnicos y su utilización simbólica vienen a ofrecernos una visión de totalidad al considerar la manera como están integrados para trasmitirnos esa visión del mito de Orfeo. Los mismos personajes se ven arrastrados por sus impulsos amorosos que van más allá de su condición y del mundo en el que se mueven, pero las condiciones que marcan su existencia (si se puede hablar así de todos ellos), dan como resultado la consagración definitiva de
Orfeo, pues al renunciar la Muerte a su objeto, convertirá en inmortal al poeta.

El manuscrito encontrado en Zaragoza (Rekopis znaleziony w Saragossie, Wojciech Has, 1964)

Nos encontramos ante una película que afronta el reto de adaptar una de las obras más destacadas de la literatura fantástica; la novela del conde Jan Potocki (1761-1815) representa una de las aportaciones literarias más interesantes de la época de la llustración, y que, además, a lo largo del siglo XIX y XX se vio sometida a muy diversos avatares y ediciones parciales hasta que a finales del pasado siglo XX se pudo tener una visión global de aquel amplio y complejo mundo que se nos trasmitía en sus páginas.

La intrincada estructura de que está dotada la novela, merced a la integración sucesiva de historias que se encabalgan conforme avanza la acción (o mejor dicho, las acciones), hace que nos encontremos ante una de las fórmulas más originales y complejas de la literatura, lo cual ha dado lugar a interesantes interpretaciones de un mundo lleno de riqueza, matices de gran sutileza, integración de claves muy diferentes, referencias a aspectos sociológicos, esotéricos, teológicos o históricos que hace que cada página esté dotada de una fuerza e interés indudables. ${ }^{23}$

Lo primero que tenemos que apuntar es que la versión cinematográfica que comentamos no adapta nada más que una parte limitada de la gigantesca obra de Potocki (algunas de las jornadas de la parte inicial de la novela) dejando fuera muchos elementos, a pesar de lo cual sorprende la coherencia interna lograda dentro de la gran dificultad que presenta el conjunto.

Es sorprendente el paralelismo que se produjo entre novela y película en relación a su vida pública de cara a lectores y espectadores respectivamente; si a lo largo de dos siglos solamente se produjeron ediciones parciales de la novela, la película no corrió mejor suerte, puesto que su duración original de 182 minutos fue cercenada desde el mismo momento de su estreno con distribución de copias de muy inferior duración. Será finalmente en 1997 cuando de la mano de Francis Ford Coppola y Martin Scorsese se estre- 
nará en Estados Unidos la versión original que posteriormente sería trasformada a DVD ${ }^{24}$ y sobre la que realizaremos nuestro estudio.

Desde el primer momento llama la atención el difícil equilibrio entre realidad e ilusión que nos ofrecen las imágenes. Esta interesante circunstancia ya había sido apuntada en relación a la obra literaria por Todorov cuando resaltaba que se nos ofrecían "una serie de acontecimientos ninguno de los cuales, tomado aisladamente, contradice las leyes de la naturaleza... pero su acumulación ya plantea problemas". ${ }^{25}$

En la película este carácter realista se refuerza por el tipo de puesta en escena que ha utilizado el director; los decorados son totalmente reales reafirmando el naturalismo del mundo en que se encuentran inmersos los protagonistas, los ambientes son reconocibles, aunque los vinculemos a la visión del mundo hispano que se tenía en la llustración (vestuarios, folklore, costumbres), pero ello se enriquece y adquiere una dimensión diferente cuando los contemplamos abriéndose a una nueva perspectiva que los trasciende. ${ }^{26}$

Todo ello nos habla del cuidado y riqueza con que Has y sus colaboradores (el fotógrafo Mieczysław Jahoda, el director artístico Jerzy Skarżyński, también responsable del vestuario, junto con el decorador Tadeusz Myszorek, y el músico Krzysztof Penderecki) han afrontado la complejidad de la obra; para ello han recurrido a referentes pictóricos de muy diversos tipos, desde autores como Dalí o Magritte a simbolistas de muy diferentes matices, logrando de esa manera que el mundo fantástico que se nos presenta adquiera un claro matiz surrealista (de ahí la admiración de Buñuel hacia esta obra), lo que ha quedado evidenciado, por ejemplo, en los bocetos que figuran en los títulos de crédito, sin olvidar la referencia al mundo goyesco que aflora en determinados momentos de la película.

De igual manera sorprende la rica banda sonora construida por Penderecki en la que se unen las reinterpretaciones del clasicismo del XVIII con fragmentos de clara inspiración en las música de raíz hispana, sin olvidar los momentos en los que las fórmulas atonales, tan del gusto de este compositor, ayudan a trasmitir ese mundo mistérico que subyace en muchas de las imágenes. ${ }^{27}$
Pero si la obra de Potocki ha sido admirada y estudiada, lo mismo que su adaptación cinematográfica, es por su estructura narrativa, llena de rasgos de indudable interés y que plantea una serie de reflexiones sobre aquello que se nos cuenta y la forma de hacerlo. Porque la eterna discusión sobre el equilibrio entre estos dos extremos se evidencia de manera meridiana, como dice de manera ajustada Diego Moldes:

Nos encontramos ante una estructura que tiende hacia el infinito, un abismo en espiral que sube $y$ se desborda como un relato sin fin, en el que un cuento incluye otra historia que a su vez nos lleva a otra narración, que también integra otro relato que a su vez conecta con el primero..... Es la forma, aqui, la que determina el fondo. ${ }^{28}$

La estructura en espiral es fascinante a lo largo de toda la película, puesto que las situaciones se reiteran de manera continua, de tal forma que aunque sabemos que la acción avanza podemos llegar a percibir la sensación de que reiteradamente volvemos a un punto ya conocido.

Se ha recurrido con frecuencia a comparar esta forma narrativa con la conocida figura de las muñecas rusas que contienen en su interior otra imagen semejante, y así de manera continua; aquí se produce un encadenamiento de las historias que se nos cuentan, de forma que partiendo de una situación inicial vamos descubriendo sucesivas concomitancias que nos arrastran continuamente. En este sentido hay unos momentos significativos en el film cuando se encadenan sucesivamente las historias de Avadoro, el señor Toledo, Lope Suárez, su padre, el banquero Moro, don Roque Busqueros, Frasquita Salero, Inés Moro, el conde Peña Flor y varios más, acompañados de reiterados avances y retrocesos, lo cual hace que Alfonso Van Worden, protagonista del film llegue a decir "Ya no sé dónde acaba la realidad y dónde empieza la ficción".

Para poder llevar adelante todo este planteamiento Has (y el guionista Tadeusz Kwiatkowski) recurren, no sólo, a una sucesión de "flashback" y "flash-forward", sino sobre todo, a una ausencia de cualquier tipo de recurso visual que pueda servir al espectador como hilo conductor. No podemos olvidar que la película surge en un momento de la historia del cine (años sesenta del siglo pasado) en el que se produce una ruptura 
de las estructuras narrativas clásicas que habían estado consagradas en las décadas anteriores, y que la manipulación del tiempo y el espacio será una de las marcas definidoras de estos nuevos cines (fig. 3). ${ }^{29}$

La importancia de representación del tiempo en este relato cinematográfico (que convirtió al film en un caso singular en la historia del cine) se debe a que es distorsionado en tres aspectos fundamentales como son el orden de exposición, la duración de cada fragmento y su frecuencia, ${ }^{30}$ buscando la participación del espectador que se siente arrastrado en la vorágine de acontecimientos encadenados que se le presentan y crean una fascinación hasta alcanzar a comprender ese mundo en el que se encuentra enredado.

Esta vacilación del espectador (elemento apuntado como fundamental por Todorov para entender lo fantástico ${ }^{31}$ ) ante un mundo espaciotemporal difícil de asimilar como conjunto será, de esta forma, un elementos básico para comprender esta obra. Esto lleva al reconocimiento de que lo simbólico y onírico llegan a alcanzar una prevalencia sobre otros factores estéticos, lo que confiere al film de un fuerte carácter surrealista; a ello coadyuva el erotismo, fuertemente presente en la obra literaria y con una relevancia especial en la atención concedida al mundo lésbico, que impregna muchas de las historias que se nos narran, y que Has nos trasmite aprovechando las rupturas y libertades (hasta cierto punto sorprendentes en la Polonia del momento) que iban teniendo cada vez mayor presencia en el cine internacional de la época.

La última conclusión a la que podemos llegar ante el visionado de El manuscrito encontrado en Zaragoza es el reconocimiento de la fuerza inconmensurable de la imagen animada, la riqueza de matices que pueden aglutinarse en cada plano o secuencia el film y la constatación de que no existe un único modo de ver e interpretar la realidad.

\section{Goya en Burdeos (Carlos Saura, 1999)}

Après Goya, commence la peinture moderne André Malraux

Esta frase del famoso pensador francés, traducida al español, cierra la película de Carlos Saura. Es un claro indicador de la admiración que este

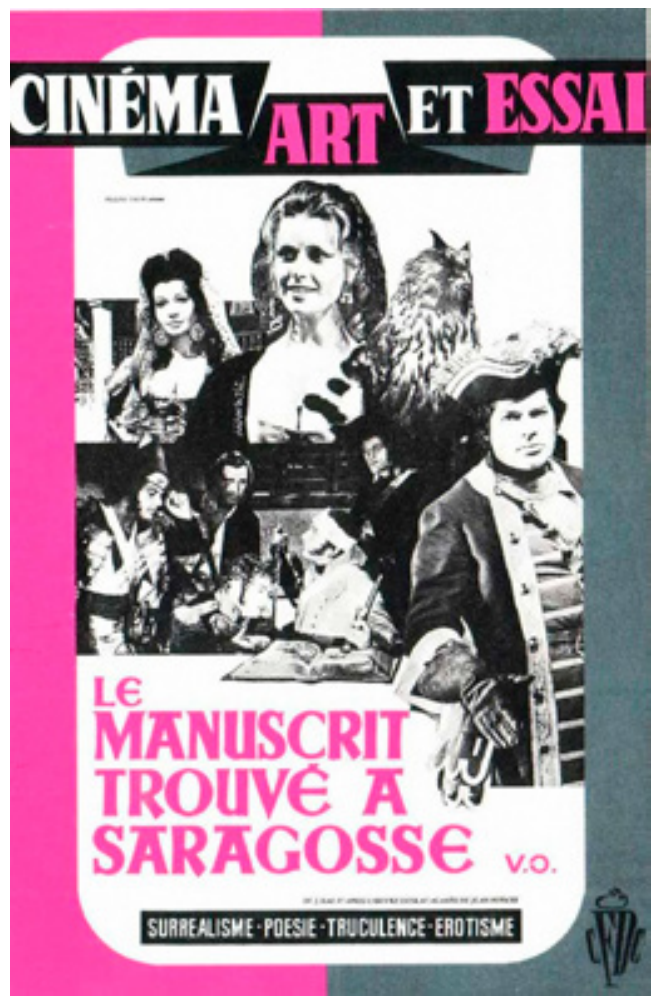

Fig. 3. Rekopis znaleziony w Saragossie, El manuscrito encontrado en Zaragoza, Wojciech Has, 1964

director siente hacia el pintor y que va más allá de la afinidad por orígenes aragoneses comunes o por la influencia trasmitida en este sentido por su hermano, el pintor Antonio Saura a quien está dedicado el film, y su admirado paisano Luis Buñuel.

Más allá de estos aspectos, que son innegables, hay dos facetas que fueron asumidas tanto por Goya como por Saura y que subyacen de manera radical en la película que comentamos: por una parte, la vinculación con el contexto histórico que les correspondió vivir a los dos y, por otra, la lucha continua por encontrar caminos expresivos artísticos nuevos a lo largo de sus vidas profesionales.

El paralelismo entre ambos artistas y la forma de desarrollar estas dos claves consideramos que se convierten en el soporte básico del análisis de la película, de tal manera que podemos desarrollar una serie de argumentaciones que muestren la confluencia de aspectos que dan como resulta- 
do una riqueza artística que convierte a este film en una de las manifestaciones cinematográficas más ricas y sugerentes de las últimas décadas.

Desde el mismo título constatamos que nos encontramos ante una biografía cinematográfica atípica ("biopics" en terminología anglosajona) ${ }^{32}$, dotada de la singularidad de que en ella Saura sabe fundir todas aquellos puntos de vista que pueden adoptarse en este tipo de obras: la vertiente documental (situar al artista en su entorno), la especular (el pintor en su trabajo) y la interpretativa (el director da su visión sobre lo que representa) ${ }^{33}$, con lo que la sensación de totalidad se trasmite al espectador de forma sutil.

En relación con el contexto histórico destaca desde el primer momento la importante documentación de la que ha partido Saura al construir el guion y llevarlo a imágenes ${ }^{34}$, desde la correspondencia con sus amigos (Leandro Fernández de Moratín y Zapater ${ }^{35}$ ), los elementos escénicos (vestuario, decorados) y musicales, los diferentes métodos de trabajo pictórico (tablas, frescos, litografías), hasta la importante presencia de obras realizadas por el pintor ${ }^{36}$, son elementos de gran importancia a nivel individual y que, en conjunto, configuran un soporte imprescindible para que podamos acercarnos de manera muy interesante a diferentes momentos de la vida del protagonista.

Todo ello le permite a Saura asumir un reto tan interesante como realizar la trasposición cinematográfica del imaginario goyes $\mathrm{CO}^{37}$, pues a lo largo del film contemplamos aquellos grandes conceptos y principios que subyacen en las obras del pintor, los ideales que fueron cristalizando a lo largo de los años y, de una manera radical, aquellos elementos icónicos que se convirtieron en signos de identificación de su trabajo. Se ha comentado ${ }^{38}$ que la estructura metatextual se basa en un juego de espejos: el correspondiente a Goya que interpreta el contexto histórico, mientras que el de Saura se acerca al estudio del pintor.

Para trasmitirlo en imágenes animadas, nuestro director adopta una estructura temporal muy interesante y que explicita la fuerza y versatilidad del cine para acercar al espectador a mundos cronológicamente diferentes. La seductora, y a la vez inquietante, figura de la espiral subyace en el conjunto del film, pues partimos de los últi- mos tiempos del pintor en Burdeos, hasta llegar a su muerte, momento en el que volvemos al punto inicial de aquella vida con su nacimiento en Fuendetodos.

Además, a lo largo de toda la obra se va produciendo la alternancia de lo que podemos considerar el presente (vida bordelesa) con diferentes momentos (personales y sociales) por los que pasó a lo largo de su existencia; la forma como se van presentando estos avatares es muy sugerente, llena de efectividad y nos permite conseguir una visión de conjunto de sus relaciones sociales y profesionales, facilitando una progresión narrativa de gran efectividad. ${ }^{39}$

A fin de reafirmar la integración de esos momentos pasados con el presente, Saura utiliza una serie de códigos sonoros; el encabalgamiento musical que nos facilita pasar de una secuencia a otra (Fandango de Boccherini o la canción del siglo XVI No hay que decirle el primor) nos llevan de manera sutil hacia aquellos momentos que, aun habiendo pasado, todavía permanecen presentes para nosotros o establecen una relación entre ambas imágenes. Además la alternancia sonora de las voces del joven y el viejo Goya crea una continuidad por encima del paso del tiempo y una fusión temporal de manera que "conduce a un rico diálogo entre lo que es, lo que fue, lo que desea ser y lo que pudo ser"40; así el espectador se ve envuelto en una continuidad narrativa que permite presentar momentos distintos y la relación entre etapas que están alejadas temporalmente pero unidas psicológicamente.

A ello se unen las secuencias en las que nos presenta al protagonista en dos momentos (e intérpretes) diferentes dentro del mismo plano; no podemos olvidar que este recurso fue uno de los más significativos de un film tan importante en la filmografía de Saura como La prima Angélica (1973), con lo que se refuerza la integración entre momentos diferentes de una misma vida.

Toda esta recreación temporal se ve reforzada de manera muy sugestiva por la presencia de testimonios gráficos de la gran variedad de obras que Goya realizó a lo largo de su vida, si bien ello se realiza con fórmulas diferentes que reflejan la diversidad de momentos, temas y técnicas usadas por el pintor; de esa manera podemos ver como se unen el relato literario y el pictórico 
(realización de la cúpula de San Antonio de la Florida), la integración de los personajes como fondo pictórico (pasillo lleno de retratos ${ }^{41}$ o visión de la Quinta el Sordo) o la integración de fragmentos en una estructura narrativa unitaria (Desastres de la guerra ${ }^{42}$, a lo que se unen las referencias sobre su admiración por Velázquez y su forma de conseguir el sentido del espacio en Las Meninas ${ }^{43}$ (fig. 4).

Y por último, la luz. No podemos finalizar nuestras reflexiones sobre Goya en Burdeos sin dedicar unos párrafos a la importancia que tiene la luz y sus variables expresivas en manos de Saura y sus colaboradores. Destaca en el conjunto del film la representación de los decorados de una forma tan sugestiva como son esas paredes construidas "sobre bastidores de aluminio cubiertos por "opera foil" (material plástico ignífugo y traslúcido)" ${ }^{44}$, lo que crea una sensación de fantasmagoría a la vez que establecen nexos de unión entre ambientes diferentes.

Tampoco podemos pasar por alto los recursos lumínicos (y las consiguientes variables cromáticas) que alcanzan una especial consideración en determinadas secuencias; se trata, fundamentalmente, de recreaciones de determinados temas goyescos que superan la mera consideración de "tableaux vivants" a que nos tiene acostumbrado el cine histórico.

Son tres los momentos que podemos destacar: el paseo de Goya por la pradera de San Isidro cuando busca la inspiración para la pintura de San Antonio de la Florida y nos presenta tipos humanos, bailes y actividades diversas, pero sobre todo esa luz tan peculiar que nos ofrece Madrid desde el otro lado del Manzanares. Junto a ello llama la atención una secuencia totalmente ficticia sobre los juegos femeninos en la Corte, construida sobre colores pastel e inspiración en tablones para tapices que recogen muchas de esas costumbres.

La última de estas recreaciones, y la más destacable, es la reinterpretación de Los desastres de la guerra. Nos encontramos con dos contribuciones muy interesantes para conseguir el resultado que contemplamos: Vittorio Storaro y La Fura dels Baus. El gran director de fotografía italiano nos ofrece una diversidad y riqueza cromática en la que juega con una gran versatilidad, de tal ma-

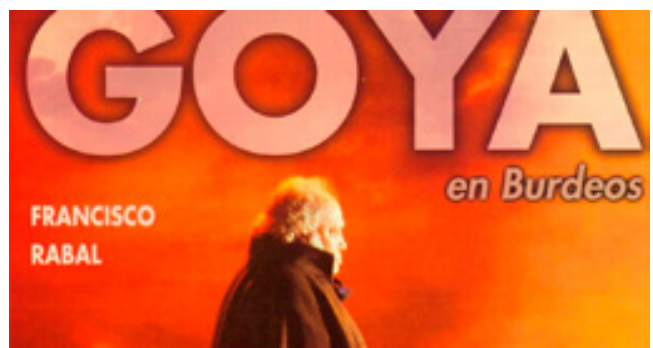

Fig. 4. Goya en Burdeos, Carlos Saura, 1999

nera que el espectador percibe con gran fuerza la crudeza de las situaciones que se explicitan. ${ }^{45} \mathrm{Se}$ trata de uno de los ejemplos más interesantes de cómo la luz cinematográfica puede alcanzar niveles de expresividad y sensibilidad resaltables, a la vez que permite profundizar en unas imágenes que, de esa forma, se convierten en recreación de unas imágenes que pertenecen a la historia mundial del grabado.

A ello se une la creatividad de La Fura dels Baus. Este grupo teatral catalán, que ya había colaborado con Saura en Maratón, película filmada con ocasión de los Juegos Olímpicos de Barcelona en 1992, nos ofrece en esta ocasión un ejemplo magnífico de su creatividad; la forma como nos reinterpreta algunos de los grabados de Los desastres de la guerra permite reflexionar sobre la fuerza de la imagen en movimiento más allá de lo que sean los elementos de partida, a lo que se une la versatilidad y dureza de lo representado, consiguiendo con esta secuencia un magnífico colofón al conjunto que es la película.

Junto a ello, el color blanco. Este color es uno de los más significativos en manos de Saura, puesto que no solo está presente en múltiples momentos del film (importancia del camisón que lleva Goya en muchas secuencias y las paredes traslúcidas que hemos comentado), sino que adquiere especial importancia cuando nos acercamos a la muerte del protagonista, llegando a ser un elemento determinante en la última secuencia de la obra ${ }^{46}$. Ese blanco parece una ruptura de nuestros códigos convencionales sobre la muerte (como hemos visto en otras películas comentadas anteriormente), con lo que se crea una interpretación positiva de la vida de nuestro protagonista y, sobre todo, su proyección de cara al futuro y permanencia por encima del paso del tiempo. 
El poliedro transparente o la riqueza de las imágenes cinematográficas

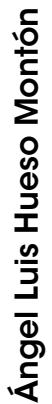

Todas las reflexiones realizadas en este trabajo las aportaciones de ámbitos muy diferentes que ponen de manifiesto la riqueza de la imagen cisiempre deberán ser tenidas en cuenta para ponematográfica y, en concreto, lo que representan der comprender el valor y profundidad del cine. 


\section{NOTAS}

1 "Una creatividad colectiva en la que los miembros de un equipo participan en la realización de una sola obra, por medio de una continua interacción". J. F. Scott, el cine, un arte compartido, EUNSA, Pamplona, 1979, p. 45.

2 J. Mitry, Estética y Psicología del Cine. I Las estructuras, Siglo XXI, Madrid, 1978, p. 25.

${ }^{3}$ Estos matices se pierden en los títulos con que se lanzó la película tanto en el mercado norteamericano ("Destiny" Destino) como en las salas francesas ("Les trois lumières", Las tres luces).

${ }^{4}$ S. Kracauer, De Caligari a Hitler. Una historia psicológica del cine alemán, Paidós, Barcelona, 1995 ( $1^{\text {a }}$ edición 1947), p. 91.

${ }^{5}$ P. M. Jensen, Fritz Lang, Ediciones JC, Madrid, 1990 ( $1^{\text {a }}$ edición 1969), p. 31.

6 S. Socci, Fritz Lang, editrice II Castoro, Milán, 1994, p. 25.

7 Cantar de los Cantares, 8, 6.

8 Jensen, Ob. Cit., p. 32.

${ }^{9}$ Muchos de los datos son aportados por el propio Herman Warm en "Les tres lumières". Cinematographe, $n^{\circ}$ 75, fevrier 1982, pp. 5-7. Resalta el exquisito trabajo llevado a cabo por Röhring al crear la sala de las luces de la vida, así como la armonía que existió entre los tres decoradores para superar satisfactoriamente las tensiones que surgieron.

${ }^{10}$ Kracauer, Ob. Cit., p. 91.

${ }^{11}$ L. Eisner, Fritz Lang, Flammarion, París, 1988, p. 52.

${ }^{12} \mathrm{~V}$. J. Benet, "La muerte y la doncella (Espacio y encuadre en Der Müde Tod)", en Más allá de la duda. El cine de Fritz Lang, (V. J. Biosca, coord..), Universitat, Valencia, 1992, p. 26.

${ }^{13} \mathrm{~L}$. Eisner, L'écran démoniaque. Les influences de Max Reinhardt et de I'Expressionisme, Le Terrain Vague, Eric Losfeld, 1985 (1ºdición 1952), p. 65.

${ }^{14}$ Ibidem, p. 64.

${ }^{15}$ P. Pedraza, Jean Cocteau. El gran ilusionista, Shangrila, Santander, 2016, p. 115.
${ }^{16}$ L. Sancho Rodríquez, Una tinta de luz. La poesía cinematográfica de Jean Cocteau, Universidad del País Vasco, Bilbao, 2008, p. 151.

${ }^{17}$ Recogido por T. Fernández Valentí, "Orfeo", Dirigido por", no 348 (2005), p. 45.

${ }^{18}$ D. Martínez Ramírez, "Estrellarse contra la superficie", HipoTesis, 4, 2016, p. 47.

${ }^{19} \mathrm{R}$. Sardá Sánchez y V. Alemany Sánchez-Moscoso, "Jean Cocteau frente el espejo de Orfeo", Index Comunicación, n 7 (2), 2017, p. 77. 137.

${ }^{20}$ Sancho Rodríguez, Ob. Cit. P.

${ }^{21}$ Sancho Rodríguez, Ob. Cit., p. 139

${ }^{22}$ Pedraza, Ob. Cit., p. 130.

${ }^{23}$ Véase el interesante trabajo de A. Domínguez Leyva, El laberinto imaginario de Jan Potocki. Manuscrito encontrado en Zaragoza (Estudio crítico), Universidad Nacional de Educación a Distancia, Madrid, 2000.

${ }^{24} \mathrm{D}$. Moldes, El manuscrito encontrado en Zaragoza. La novela de Jan Potocki adaptada al cine por Wojciech Jerzy Has, Calamar Ediciones, 2009, pp. 48-52.

${ }^{25} \mathrm{~T}$. Todorov, Introducción a la literatura fantástica, editorial Tiempo Contemporáneo, Buenos Aires, 1972, p. 37.

${ }^{26} \mathrm{R}$. Cueto, "El manuscrito encontrado en Zaragoza", en Vientos del Este. Los nuevos cines en los paises socialistas europeos (1955-1975) (J. E. Monterde y C. Losilla, coords.), Institut Valenciá de Cinematografía, Festival Internacional de Cine de Gijón, centro Galego de Artes da Imaxe, Filmoteca Española, Valencia, 2006, p. 220.

${ }^{27}$ Moldes, Ob. Cit., pp. 75-78.

${ }^{28}$ Moldes, Ob. Cit., p. 29

29 J. Hernández Ruiz, "Has, Wojcieck Jerzy", en Vientos del Este. Los nuevos cines en los paises socialistas europeos (1955-1975), p. 290.

${ }^{30}$ Moldes, Ob. Cit., p. 68

${ }^{31}$ Todorov, Ob. Cit., pp. 42-43.

${ }^{32}$ No puede pasarse por alto el interés de Saura por las biografías de determinados personajes históricos y que ha ido desarrollando a lo largo de su filmografía. Así se acercó a José
María Hinojosa "El Tempramlo" (Llanto por un bandido, 1963), Antonieta Rivas (Antonieta, 1982), Lope de Aguirre (Eldorado, 1987), San Juan de la Cruz (La noche oscura, 1988), Goya (Goya en Burdeos, 1999), y Luis Buñuel (Buñuel y la mesa del rey Salomón, 2001).

${ }^{33} \mathrm{~N}$. Berthier, "Carlos Saura ou l'art d'heritier", en Goya en Burdeos de Carlos Saura, (J.-P. Castellani (coord..), Editions du Temps, Nantes, 2005, p. 205.

${ }^{34}$ Algo similar sucedía en La noche oscura recogiendo textos de San Juan de la Cruz. Véase A. L. Hueso Montón, "Quién podrá escribir lo que a las almas amorosas donde Él mora hace nacer ( $L a$ noche oscura, Carlos Saura, 1989)" , en Desmontando a Saura (C. RodríguezFuentes (coord.), Luces de Gálibo, Barcelona, 2013, pp. 145-158.

${ }^{35} \mathrm{M}$. Águeda Villar, "Goya en relato cinematográfico", Cuadernos de Historia Contemporánea, n²3 (2001), p. 93.

${ }^{36}$ En este sentido son imprescindibles los trabajos de J. Soubeyroux, "Index commenté des oeuvres de Goya dans Goya en Burdeos" en De Goya à Saura (J.-P. Aubert y J.-C. Seguin (coords.), Le Grimm, Lyon, 2005, pp. 95- 124, y J.-C. Seguin, "Les résurgences picturales dans Goya en Burdeos", Ibidem, pp. 125- 162.

${ }^{37}$ V. J. Stoichita, "Lámpara descomunal. Goya y el cine", en El Museo del Prado y el Arte Contemporáneo. La influencia de los grandes maestros del pasado en el arte de vanguardia, Galaxia Gutemberg-Círculo de Lectores, Madrid, 2007, p. 173.

${ }^{38} \mathrm{~S}$. García Ochoa, "Goya en el laberinto del autor", en Goya en Burdeos de Carlos Saura, p. 154.

${ }^{39}$ Véase el interesante trabajo de N. Berthier, "Memento mori: réflexions sur le Temps dans Goya en Burdeos de Carlos Saura" en De Goya à Saura, pp. 191-207.

${ }^{40}$ A. Gómez Gómez, "Retrato imaginario de Goya por Carlos Saura", en Desmontando a Saura, p. 98.

${ }^{41}$ Se ha apuntado la posible influencia del montaje teatral de El sueño de la razón, de Buero Vallejo, dirigida por José Osuna y estrenada en el teatro Reina Victoria, de Madrid, en 1970 y repuesta en el teatro María Guererro, 
${ }^{44} \mathrm{C}$. Saura Atarés, "Goya (Goya en Burdeos). Apuntes para una película sobre Goya escrita y dirigida por Carlos Saura", Artigrama, n 11 (1994), pp. 11-78, en concreto p. 12.

${ }^{45}$ Muy interesantes reflexiones en J.-C. Seguin, "Mehr Licht", en De Goya à Saura, pp. 209-226, y E. Otero Váz- quez, "Filmando la Historia. La pìntura de Goya como referente visual en el cine histórico español", en V Congreso Internacional de Historia y Cine. Escenarios del Cine Histórico (Gloria Camarero (coord.), Madrid, (2016), p. 435

${ }^{46} \mathrm{~J} .-\mathrm{P}$. Aubert, "Goya en Burdeos: un "portrait imaginaire", en de Goya à Saura, p. 168 


\section{REFERENCIAS}

Águeda Villar, M. 2001. "Goya en relato cinematográfico." Cuadernos de Historia Contemporánea 23: 67-102.

Aubert, J.-P. 2005. "Goya en Burdeos: un "portrait imaginaire." In De Goya à Saura, J.-P. Aubert y J.-C. Seguin, coords. Lyon: Le Grimm.

Benet, B. J. 1992. "La muerte y la doncella (Espacio y encuadre en Der Müde Tod)." In Más allá de la duda. El cine de Fritz Lang, edited by V. J. Biosca. Valencia: Universitat de Valencia.

Berthier, N. 2005. "Memento mori: réflexions sur le Temps dans Goya en Burdeos de Carlos Saura." In De Goya à Saura, J.-P. Aubert y J.-C. Seguin, coords., 191-207. Lyon: Le Grimm.

Berthier, N. 2005. "Carlos Saura ou l'art d'heritier." In Goya en Burdeos de Carlos Saura, J.-P. Castellani, coord. Nantes: Editions du Temps.

Cueto, R. 2006. "El manuscrito encontrado en Zaragoza." In Vientos del Este. Los nuevos cines en los países socialistas europeos (19551975), J. E. Monterde y C. Losilla, coords. Valencia: Institut Valenciá de Cinematografía, Festival Internacional de Cine de Gijón, Centro Galego de Artes da Imaxe, Filmoteca Española.

Domínguez Leyva, A. 2000. El laberinto imaginario de Jan Potocki. Manuscrito encontrado en Zaragoza (Estudio crítico). Madrid: Universidad Nacional de Educación a Distancia.

Eisner, L. 1985. L'écran démoniaque. Les influences de Max Reinhardt et de l'Expressionisme (1 $1^{a}$ edición 1952). Le Terrain Vague, Eric Losfeld.

Eisner, L. 1988. Fritz Lang. Paris: Flammarion.

Fernández Valentí, T. 2005. "Orfeo." Dirigido por 348: 45.

García Ochoa, S. 2005. "Goya en el laberinto del autor." In Goya en Burdeos de Carlos Saura, J.-P. Castellani, coord. Nantes: Editions du Temps.

Gómez Gómez, A. 2005. "Trampantojos cinematográficos o el diálogo entre las artes." Paradigma 1: 12-15
Gómez Gómez, A. 2013. "Retrato imaginario de Goya por Carlos Saura." In Desmontando a Saura, C. Rodríguez-Fuentes, coord. Barcelona: Luces de Gálibo.

Hueso Montón, A. L. 2013. "Quién podrá escribir lo que a las almas amorosas donde Él mora hace nacer (La noche oscura, Carlos Saura, 1989)." In Desmontando a Saura, C. Rodríguez-Fuentes, coord., 145-158. Barcelona: Luces de Gálibo.

Jensen, P.M. 1990. Fritz Lang (1ª edición 1969). Madrid: ediciones JC.

Kracauer, S. 1995. De Caligari a Hitler. Una historia psicológica del cine alemán ( $1^{\text {a }}$ edición 1947). Barcelona: Paidós.

Martínez Ramírez, D. 2016. "Estrellarse contra la superficie." HipoTesis 4: 47.

Mitry, J. 1978. Estética y Psicología del Cine. I Las estructuras. Madrid: Siglo XXI.

Moldes, D. 2009. El manuscrito encontrado en Zaragoza. La novela de Jan Potocki adaptada al cine por Wojciech Jerzy Has. Madrid: Calamar Ediciones.

Pedraza, P. 2016. Jean Cocteau. El gran ilusionista. Santander: Shangrila.

Otero Vázquez, E. 2016. “Filmando la Historia. La pintura de Goya como referente visual en el cine histórico español." In V Congreso Internacional de Historia y Cine. Escenarios del Cine Histórico, Gloria Camarero, coord. Madrid.

Sancho Rodríquez, L. 2008. Una tinta de luz. La poesía cinematográfica de Jean Cocteau. Bilbao: Universidad del País Vasco.

Sardá Sánchez, R., and Vicente Alemany Sánchez-Moscoso. 2017. "Jean Cocteau frente el espejo de Orfeo." Index Comunicación 7 (2): 77.

Saura Atarés, C. 1994. "Goya (Goya en Burdeos). Apuntes para una película sobre Goya escrita y dirigida por Carlos Saura." Artigrama 11: 11-78.

Scott, J.F. 1979. El cine, un arte compartido. Pamplona: EUNSA. 
Seguin, J.-C. 2005. "Mehr Licht." In De Goya à Saura, J.-P. Aubert y J.-C. Seguin, coords., 209-226. Lyon: Le Grimm.

Seguin, J.-C. 2005. "Les résurgences picturales dans Goya en Burdeos." In De Goya à Saura, J.-P. Aubert y J.-C. Seguin, coords., 125- 162. Lyon: Le Grimm.

Socci, S. 1994. Fritz Lang. Milano: editrice II Castoro.

Soubeyroux, J. 2005. "Index commenté des oeuvres de Goya dans Goya en Burdeos." In De Goya à Saura, J.-P. Aubert y J.-C. Seguin, coords., 95- 124. Lyon: Le Grimm.
Stoichita, V.J. 2007. "Lámpara descomunal. Goya y el cine." In El Museo del Prado y el Arte Contemporáneo. La influencia de los grandes maestros del pasado en el arte de vanguardia. Madrid: Galaxia Gutemberg-Círculo de Lectores.

Todorov, T. 1972. Introducción a la literatura fantástica. Buenos Aires: editorial Tiempo Contemporáneo.

Warm, Herman. 1982. "Les tres lumières." Cinematographe 75 (Fevrier): 5-7. 
